\title{
Development of remote monitoring system for biomedical equipment
}

\begin{abstract}
Introduction: Videolaparoscopy is an effective technique to access the body cavities. This technique maintains a minimal invasive impact in relation to other surgical procedures. However, in order to accomplish this technique it is necessary to have trained health professionals and an appropriate, robust set of equipment. The objective of this article is to present and describe a remote monitoring system which was developed to monitor and assistance precision biomedical equipment, such as the ones used for videolaparoscopy. This monitoring system, VERA, implements a collaborative methodology between health professionals and equipment maintenance professionals. The system was designed using the $3 \mathrm{C}$ model to provide the collaborative characteristics. Moreover, the development and implementation used web technologies. Throughout this process, modeling of the VERA system included conceptual and technical methods such as wireframes, site map and user interaction modeling. The VERA system allowed a collaborative work environment for the technical assistance team (for maintenance purposes) and the health professional responsible for the videolaparoscopy. The steps developed so far reveal that the system developed through the $3 \mathrm{C}$ model contributes to the creation of a collaborative environment in the remote monitoring of videolaparoscopic medical equipment. This, in turn, allows the technical assistance team to carry out diagnostic and maintenance with celerity, making it possible to ensure precise and efficient procedures in the Brazilian Unified Health System.
\end{abstract}

Keywords: remote monitoring, videolaparoscopy, 3C model, biomedical equipment, VERA
Volume 3 Issue 3 - 2017

\author{
Felipe Soares Macedo,' Suélia De Siqueira \\ Rodrigues Fleury Rosa, ${ }^{2}$ Mário Fabrício \\ Fleury Rosa, ${ }^{3}$ Guilherme Henrique \\ Rodrigues Vaz, ${ }^{4}$ Gilvandson Costa \\ Cavalcante, ${ }^{5}$ Isabela MCDMN Souza, ${ }^{6}$ Luiz \\ Fernando Franca Medeiros ${ }^{7}$ \\ 'Postgraduate Program in Medical Sciences, University of \\ Brasilia, Brazil \\ ${ }^{2}$ Biomedical Engineering Master's Program, University of Brasilia, \\ Brazil \\ ${ }^{3}$ Postgraduate Program in Health Sciences and Technology, \\ University of Brasilia, Brazil \\ ${ }^{4}$ Postgraduate Program in Mechatronics Engineering, University \\ of Brasilia, Brazil \\ ${ }^{5}$ Deapartment of UnB Gama, University of Brasilia, Brazil \\ ${ }^{6}$ Postgraduate Program in Collective Health, Federal University \\ of Goiás, Brazil \\ ${ }^{7}$ Deapartment of Technology, University of Brasilia, Brazil
}

\begin{abstract}
Correspondence: Suélia De Siqueira Rodrigues Fleury Rosa, Deapartment of UnB Gama, University of Brasilia, Special Area of Industry Projection, East Sector, Range, Federal District,
\end{abstract} Brazil, Zip Code 72.444-240,Email rodrigues.suelia@gmail.com

Received: September 28, 2017 | Published: October 16, 2017

\section{Introduction}

In Brazil, it is the duty of the State to guarantee healthcare as a fundamental right through strategic public policies. To that end, the Unified Healthcare System (SUS in portuguese) has the resources to maintain an infrastructure that is able to promote and protect the health of its people. ${ }^{1,2}$ However, in order to achieve these goals and provide a comprehensive care to all, especially in advanced technology procedures, SUS is still striving to introduce new and efficient technologies in the realm of therapeutic and diagnostic interventions. ${ }^{3,4}$ As in the open calls for videolaparoscopy, which began in 2014, and have been extended to the present day, there is an emphasis and interest on the possibilities to bring about procedures capable of diagnosing and treating its patients through less invasive techniques. ${ }^{5}$ Videolaparoscopy is performed by accessing the pelvicabdominal cavity through the insertion of components, such as a minicamera and a cold light source, allowing internal organs to be observed on a monitor. ${ }^{6,7}$ This allows diagnostics and surgical procedures, such as bariatric surgeries (recently included in the SUS repertoire of procedures) to be performed. However, the success of such procedures directly correlate with the expertise of the professional and healthcare team involved, further placing the preventive maintenance of the videolaparoscopy equipment indispensable. ${ }^{8}$ Therefore, new initiatives to supply these requirements aim to integrate operational and managerial models that provide monitoring information on the performance of the equipment used for the therapeutic and diagnostic procedures in SUS. These include videolaparoscopes. ${ }^{9,10}$ Thence, the aim of this article is to present and describe a remote monitoring system called VERA, whose purpose is to monitor the performance of precision biomedical equipment used during videololaparoscopy techniques, through a collaborative methodology between health professionals and professionals focused in the maintenance of the equipment, within SUS.

\section{Methods and tools}

The presentation of the methods elaborates on the development of a monitoring system for biomedical equipment of high precision (VERA) in the context of videolaparoscopy procedure. The main advantage of this system is to allow the remote technical diagnosis of the equipment involved.

\section{A Proposition for a remote monitoring system}

Figure 1 illustrates the panoramic architecture of the VERA system. The latter is composed of the videolaparoscopy, concentrator equipment, and web information center. While the camera, light source, recorder and insufflator are videolaparoscopy equipment that will be monitored remotely. The concentrator is the device that collects the information of the functional parameters and alerts the equipment. This information is sent, via TCP / IP, to the information center, a Web server that centralizes the data. In addition to the medical device and equipment information, such as videolaparoscope, this information center gathers information from users and customers. It is important to clarify that the information gathered in the database of the monitoring system harnesses data from two types of users: the first coming directly from the machines and equipment being utilized, 
and the second being the data that is inserted from the technical staff using the equipment. ${ }^{11}$ In order for the VERA system to be fully utilized, it is indispensable to have access to information from users and technicians. This was possible through the collaborative systems strategies implemented, such as the $3 \mathrm{C}$ model, which was crucial to gather elements such as user interface and interaction real estate and information exchange. Therefore, the $3 \mathrm{C}$ model enabled the definition, classification and spatial distribution of the interface pertaining to the collaborative tools used. Consequently, this allowed users to communicate with one another, creating a technical support and user friendly cooperation that ensures a better work environment for these procedures. ${ }^{12}$ The information entered and stored are available for access to the electronic database on the Web. For management of information, variables and characteristics of the monitored systems, MVC (Model-View-Controller) was used. As shown in Figure 2, the system is structured in three elements that, despite interacting, can change independently. The model manages the system data and associated operations on that data. The view component defines and manages how the data is presented to the user. Finally, the controller manages user interaction (for example, typing) and transfers those interactions to the view and template. ${ }^{13}$

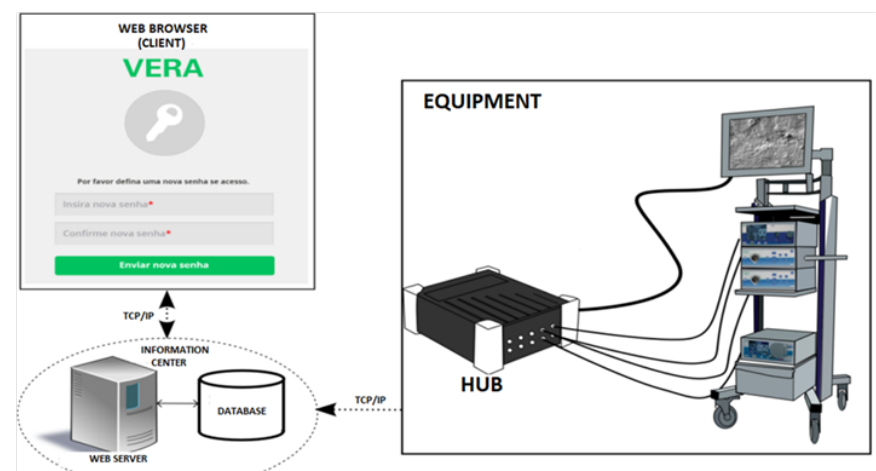

Figure I Overview of the components architecture of VERA used in the monitoring of videolaparoscopy Equipment.

To present an overview of the implementation, Table 1 summarizes the activities of the WebE framework, which describes how the tasks and methods for generating work products that contribute to the development of the collaborative system were performed. ${ }^{14}$ Communication enables developers and system stakeholders to understand the problem before beginning any procedures for resolution. This is done in order to ensure that the solution to the problem meets the needs of the user. Table 2 summarizes the functionalities and tasks that the user will execute, defined and classified according to the collaborative methodology of system development. The coordination module has information management capabilities for hospitals, medical equipment and system users. This is in addition to system help functionality, which includes videostutorials and FAQs (Frequently Asked Question).

The cooperation module offers the shared spaces both for the monitoring of the functional parameters and the current state of the biomedical equipment, as well as for monitoring the alerts of the same. This module also allows the generation of histories and reports of these parameters and alerts. Finally, the communication module allows both synchronous (textual instant messaging) and asynchronous (contact form) communication. Users who can access the system are members of the work team of the technical assistance company and the health team responsible for the procedure or diagnosis. In the elicitation that involves the categorization of users, the definition of functional requirements and creation of user interactions are done according to responsibilities, knowledge and roles, where the latter defines permissions and restrictions of access to the system. Functional requirements set the behavior of the system. Table 2 shows the functional requirements of the VERA system, which explicitly define the functionalities and services. Starting from the functional requirements are constructed the use cases of the system.

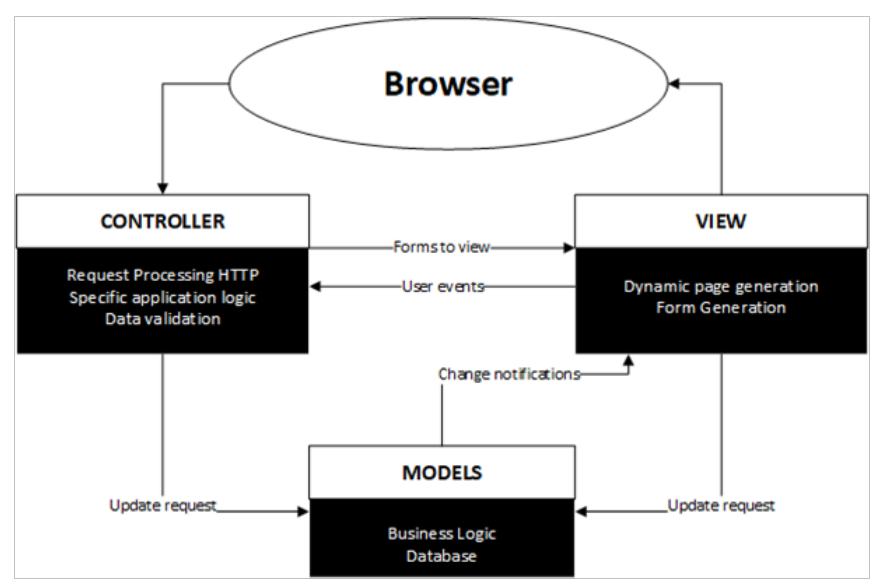

Figure 2 Diagram of the Web application utilizing the MVC software architectural pattern adapted from. ${ }^{12}$

\section{Modeling of the VERA system}

Some levels should be considered for the development of the remote system, such as: (1) conceptual and technical architecture; (2) information, covering content (wireframes) and navigational (site map); (3) interaction, which comprises interfaces, mechanisms and navigation aesthetics. Figure 3 illustrates the technical level of the conceptual architecture of the VERA system, built from the abstraction of use-case diagrams (DCU). It is possible to observe the collaborative tools classified according to the $3 \mathrm{C}$ model of the VERA system. These collaborative tools are spatially distributed in the interfaces for technicians and clients to perform their tasks from a web browser. In addition, these tools manage and present information about customers, equipment, and users stored in a database. ${ }^{12}$

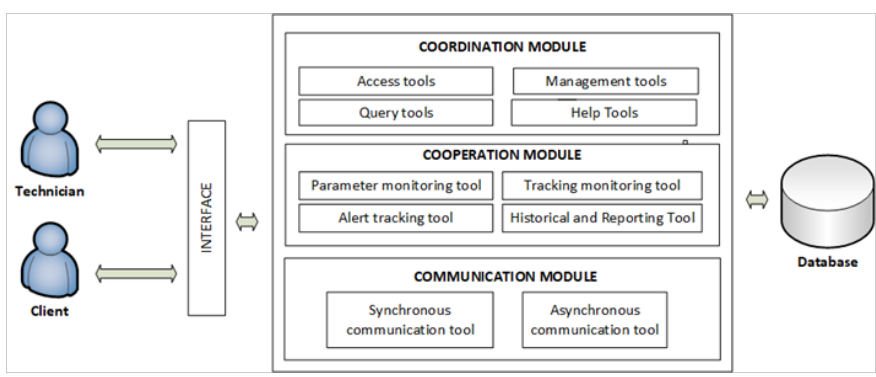

Figure 3 Conceptual architecture of the system.

While the second level of information involves content and navigational design, a web wireframe is a visual guide that represents the layout of the web page content, including interface elements, navigation mechanisms, and interaction. The objective of this work is to enable the distribution and interaction of the elements of the 3C model in user interfaces, contributing to a collaborative work environment. The interaction level, which involves the interface and aesthetic design, is based on the master wireframe, which modifies the shared work interface according to the $3 \mathrm{C}$ module tool. ${ }^{15}$ The 
interface navigation mechanism is a horizontal navigation menu that was designed according to the informational structure of the system presented in the results. The aesthetic design based on the front-end framework called bootstrap was used, with technologies such as CSS or Cascading Style Sheets, and Javascript being used to define typography, buttons, navigation menu, text boxes, labels, messages, modal windows, datapickers, notifications and wizards. The pages were designed under the concept of responsive design, which allows the interfaces ability to adapt their content according to the size of the browser screen. The build begun with the creation of the database in SQL Server 2012 and the configuration of the APS.NET MVC 5 framework in the IDE called Microsoft Visual Studio 2015.

Table I Summary of the elements pertaining to the framework WebE
Then the basic web application is generated with the system access and management components of users. From there, the software components are encoded to create the $3 \mathrm{C}$ model tools, using HTML5, CSS3, JavaScript 1.8.5, Bootstrap 3, JQuery 1.8. Team Foundation Server is used to integrate components, which offers, in addition to other services, a repository for managing and integrating the source code of the components generated by the developers. Unit tests are run to determine if the individual source code units of software components and their integration are fit for use. Wrong results from unit tests are used to refactor the components. It is worth mentioning that the tasks of coding, integration and refactoring were executed in an iterative and incremental way. ${ }^{16}$

\begin{tabular}{|c|c|c|c|c|}
\hline Activities & & Tasks & Method & Work Tools \\
\hline \multirow{4}{*}{ Communication } & \multirow[t]{2}{*}{ Formulationnnnnnn } & Formulate the problem of work & Exploratory research & System and specifications for Users \\
\hline & & Define user categories & User list analysis & User categories \\
\hline & \multirow[t]{3}{*}{ Elicitation } & $\begin{array}{l}\text { Get functional requirements and } \\
\text { system content }\end{array}$ & $\begin{array}{l}\text { Analysis of system requirements } \\
\text { system content }\end{array}$ & Functional requirements of system \\
\hline & & User Interaction schemes & User cases & Use cases \\
\hline \multirow[b]{2}{*}{ Planning } & & Carry out a risk analysis & Risk table and contingency plan & System Risks and Contingency Plan \\
\hline & \multirow{4}{*}{ Analysis Modeling } & Calendar and planning & Scrum & $\begin{array}{l}\text { Planning development strategies and } \\
\text { activities }\end{array}$ \\
\hline \multirow{5}{*}{ Modeling } & & Realize the interaction model & Use Case Diagrams UML & System use case diagrams \\
\hline & & Make the content template & Class Diagrams UML & System Class Diagrams \\
\hline & & Perform technical design & Block diagram & $\begin{array}{l}\text { Conceptual and technical architecture } \\
\text { of the system }\end{array}$ \\
\hline & \multirow[t]{2}{*}{ Design Modeling } & Carry out information design & Carry out information design & System Information Architecture \\
\hline & & Perform interaction design & $\begin{array}{l}\text { Layout of interfaces and navigation } \\
\text { mechanisms }\end{array}$ & $\begin{array}{l}\text { Structure, organization and aesthetics } \\
\text { of the system user interfaces }\end{array}$ \\
\hline \multirow[t]{2}{*}{ Construction } & & $\begin{array}{l}\text { Select, encode, create, integrate, } \\
\text { and refactor components }\end{array}$ & & System developed \\
\hline & & Evaluation & Unit Testing & System suitable for use \\
\hline \multirow{2}{*}{ Implementation } & & Create software packets & & Packed Software \\
\hline & & Publish WebApp & & System Up and running \\
\hline
\end{tabular}

Table 2 Functional requirements for the VERA System

\section{Management module}

I. The system shall provide technicians and customers with system access tools that enable:

2. Log on to the system by using user credentials;

3. Quit user session.

4. The system should provide technicians with tools that allow the management of: customers, equipment of their hospital network, users of the technical assistance company and the client

I. The system should provide the technicians with information consulting tools from: medical equipment per hospital, operating parameters per hospital and equipment, hospital and equipment alerts, and customers.

5. The system shall offer to technicians and clients, navigational monitoring by the system.

6. The system should provide the technicians and clients with the help tools, which includes video tutorials and the Frequently Asked Questions (FAQ) space.

\section{Cooperation module}

I. The system must provide technicians and customers with a shared space to monitor (every minute), graphically, the operating parameters of the equipment of each hospital.

2. The system shall provide technicians and clients with a shared space to monitor the alerts generated by the medical equipment of each hospital. 
Table Continued....

\section{Cooperation module}

3. The system must provide the technicians with a shared space to monitor the state of the alerts from the time they appear on the system until their solution.

4. The system shall provide technicians and customers with a shared space to create records and reports of the parameters of operation of the equipment and the alerts generated by them. For this purpose the system offers information search mechanisms by time interval, hospital, equipment and user.

5. The system shall provide technicians and clients with a mechanism for printing or saving the generated reports in PDF.

\section{Communication module}

I. The system should provide technicians with a chat tool that enables synchronous, text-based communication between the technical assistance team.

2. The system must provide customers with tools that allow them to contact technical assistance. This communication is asynchronous and text based.

\section{Results and discussion}

After the implementing the WebE framework iteratively, the VERA system was achieved. The interface, which can be visualized in Figure 4, integrates the collaborative tools in the remote monitoring system of videolaparoscopic medical equipment, providing technical assistance through a collaborative environment. The access tool was implemented in the login interface of the VERA system. This tool allows you to start and log off the system. In addition, it provides a navigation menu depending on the type of user that is logged in. Management tools allow you to manage customer information (hospitals), equipment, and users. Each management tool has been implemented in an interface, which organizes the information into tables. Managing this information is done using pop-up windows that add, modify, or delete tables.

The system provides query tools that allow you to filter the information presented in the alert interfaces, monitor equipment and display graphics per customer and equipment. The query tools were developed using dropdownlist. The parameter monitoring tool is implemented in the graph visualization screen of the VERA system, shown in Figure 4. This interface provides the shared space to monitor, graphically, the functional parameters of the equipment, divided into two regions: the region on the left is a checkbox list of the functional parameters of the equipment, classified by insufflator, camera, light source and recorder; the region on the right is the graphics area.

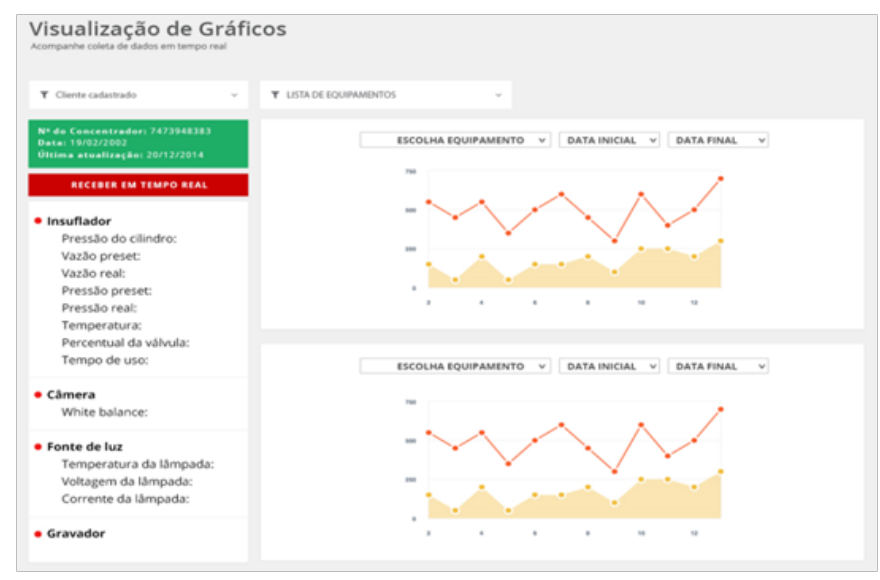

Figure 4 Workspace demonstrating the equipment monitoring panel.

Users can choose the functional parameters that are drawn in the graphics area by clicking on each checkbox. The data in the charts are updated (using AJAX) every minute. In this interface you can also see the dropdownlist of the query tool, which serves to filter the generated graphs, according to the client and the selected equipment. Furthermore, in order to monitor equipment there is a modal window of observations containing histories and reports implemented in the graphical visualization interfaces to facilitate the interpretation of information. To achieve this, the system has datapickers that allow you to choose the interval between the initial and final date for the development of reports and history logs of the functional parameters and alerts for selected equipment. Finally, this may be saved in PDF or printed.

The VERA system implements and integrates the collaborative tools for remote monitoring of medical equipment, such as videolaparoscopy equipment, as the purpose of creating a mutual scenario between technical assistance and users during technical diagnosis and maintenance. Collaborative tools are defined and classified according to the $3 \mathrm{C}$ model. Coordination tools allow you to organize and query information related to customers, equipment, and users. In addition it offers help materials for using the system. The cooperation tools provide the shared spaces to monitor and monitor the functional parameters, the current state and the alerts of the medical equipment. It also provides the mechanisms for creating histories and reports. ${ }^{15}$ Communication tools enable the exchange of information between users of the VERA system.

With the integration of the collaborative tools and their spatial distribution in the interfaces, it is possible to create the environment that allows the technical assistance team to work collaboratively. In this way, the VERA system provides the tools to organize the information, the shared spaces for the staff to work together and the communication mechanisms, so that the work team performs its tasks and makes the decisions on the diagnosis and maintenance of medical equipment, in a collaborative way. ${ }^{11,17}$ The system development process follows the guidelines of the WebE framework and takes into account, in each work product, the collaboration model 3C. The WebE framework begins with the communication activity. ${ }^{18}$ The purpose of this activity is to ensure that all stakeholders understand clearly the specifications of the VERA system. The planning activity establishes the division of tasks and working times of the team of developers in order to monitor the development of the system. The analysis modeling activity presents the DCUs and class diagrams in order for the development team to graphically understand what the system must do to perform the service tasks of the equipment. And, design modeling shows the architectures (conceptual and technical), interfaces wireframes, informational structure and interface and aesthetic designs so that the development team understands how the VERA system will be composed so that the proposed in the analysis modeling is performed. The build defines the technical tasks for 
encoding, integrating and refactoring the source code of software components. Finally, the deployment establishes the mechanisms for publishing the system on the Web. ${ }^{14}$

\section{Conclusion}

After analyzing the development thus far, it was possible to verify that the $3 \mathrm{C}$ model has a significant contribution to creating the collaborative environment in the remote monitoring system of videolaparoscopic medical equipment, allowing the technical assistance team to carry out diagnostic and maintenance with speed, enabling an efficient and precise conduct of the procedures of interest through the Brazilian Unified Health System. The authors encourage future research to use the VERA system in the various scenarios that apply to videolaparoscopy, especially situations that demand greater precision and greater equipment performance. In addition, new projections can be cited based on what has been done so far, such as the inclusion of new tools such as calendar insertion, calendars, videoconferencing insertion and application development for mobile devices such as mobile phones and tablets.

\section{Acknowledgements}

None.

\section{Conflict of interest}

The author declares no conflict of interest.

\section{References}

1. Constitution of the federative republic of brazil. 3rd ed. Brazil: Springer; 2010 .

2. LEI No 8.080/1999. Presidência da República, Brazil: 1990.

3. Castro PMV, Akerman D, Munhoz Carolina Brito, et al. Colecistectomia laparoscópica versus minilaparotômica na colelitíase: revisão sistemática e metanálise. ABCD Arq Bras Cir Dig. 2014;27(2):148-153.

4. Sussenbach S, Silva EN, Pufal MA, et al. Adesão dos cirurgiões bariátricos à laparoscopia no sistema Único de Saúde do Brasil. $A B C D$ Arq Bras Cir Dig. 2014;27(Suppl):39-42.

5. Ministério Da Saúde B. Cirurgia bariátrica por laparoscopia. In: Ministério da Saúde editors. Relatório de Recomendação, Brazil: 2016. $35 \mathrm{p}$.
6. Cavalli N, Sória HL, Danilo Galletto SSV, et al. Histerectomia vaginal assistida por videolaparoscopia associada à técnica intrafascial (HVALi) em 579 Operações. Rev bras videocir. 2003;1:128-134.

7. Pérez Martínez C De J. Historia de la cirugía laparoscópica particularidades de su introducción y desarrollo en cuba. Inicio. 2014;55(2):210

8. Cueto Gilberto L Galloso, Jiménez RAF. Consideraciones sobre la evolución histórica de la cirugía laparoscópica: colecistectomia. Rev Médica Electrónica. 2010;32(Suppl 7):1-13.

9. Fernanda Dos Santos, Gabriel Flamarim Cavasana TDC. Perfil das apendicectomias realizadas no sistema Público de Saúde do Brasil. Rev Col Bras Cir. 2017;44(1):4-8.

10. Ministério Da Saúde AN De VS. Assistência segura: Uma Reflexão Teórica Aplicada à Prátic; 2013. 172 p.

11. Cannon RM, Brock G, Buell JF. A novel classification system to address financial laparoscopic cholecystectomy. HPB Surgery:Springer; 2001. 6

12. Pimentel M, Gerosa MA, Filippo D, et al. Modelo 3C de colaboração para o desenvolvimento de sistemas colaborativos. An do III Simpósio Bras Sist Colab. 2006

13. Cordenonsi AZ, Müller FM, Fleck R. Aprendizagem Colaborativa em Mundos Virtuais 3D: analisando a colaboração sob a perspectiva do Modelo 3C de Colaboração. SBSC '13 Proceedings of the X Brazilian symposium in collaborative systems, Brazil: Springer; 2013. 96 p.

14. Pressman Roger S. Web Engineering: A Practitioner's Approach. 1st ed USA: McGraw-Hill Education; 2008.

15. Pimentel Mariano, Nicolaci-da-Costa AM. Sistemas colaborativos para uma nova sociedade e um novo ser humano. Brazil. Elsevier; 2011.

16. Sommerville I, Melnikoff SSS, Arakaki R, et al. Engenharia de software. ADDISON WESLEY BRA; 2008.

17. Pimentel Mariano, Fuks H. Sistemas colaborativos. Brazil: Elsevier; 2011.

18. Bassan Patrícia B Scherer, Barbosa Débora Nice Ferrari, Sauter Lucas Silva, et al. Cooperação e participação na educação online: a presença social no ambiente Wikispaces; 2012 